\title{
Surfactant and Counter-Ion Distribution in Styrene-Butyl Acrylate-Acrylic Acid Dry Latex Submonolayers
}

\author{
Amauri José Keslarek ${ }^{\#}$, Carlos Alberto P. Leite and Fernando Galembeck* \\ Instituto de Química, Universidade Estadual de Campinas, CP 6154, 13083-970 Campinas - SP, Brazil
}

\begin{abstract}
Submonocamadas de látex estireno-acrílico preparado usando um tensoativo sulfonato reativo e um tensoativo fosfato não-reativo foram examinadas em um microscópio de transmissão equipado com um espectrômetro de perda de energia de elétrons, para a aquisição de mapas de distribuição elementar. P está ausente do centro das partículas mas é encontrado em uma casca espessa, no fundo da imagem e em estruturas incomuns com um baixo teor de carbono, enquanto $\mathrm{S}$ está uniformemente distribuído nas partículas. Os mapas elementares de $\mathrm{Na}$ e $\mathrm{N}$ mostram que os respectivos cátions $\left(\mathrm{Na}^{+}, \mathrm{NH}_{4}^{+}\right)$têm diferentes distribuições: o sinal de $\mathrm{Na}$ é mais intenso nas partículas do que no fundo, enquanto $\mathrm{N}$ se acumula nas bordas das partículas. As distribuições de tensoativos e contraíons são portanto diferentes de algumas suposições correntes, mas elas estão de acordo com resultados recentes sobre a distribuição de constituintes iônicos em látex, obtidas por microscopia de varredura de potencial elétrico.
\end{abstract}

Styrene-butyl acrylate-acrylic acid latex submonolayers prepared using a non-reactive phosphate surfactant together with a reactive sulfonate surfactant were examined in a transmission microscope using electron energy loss spectroscopy imaging (ESI-TEM). Phosphorus is nearly absent from the particles core but it is detected in a thick shell and in unusual, strongly scattering structures with a low carbon content, and largely made out of inorganic phosphate. $\mathrm{P}$ is also dispersed outside the particles, while $\mathrm{S}$ is uniformly distributed within then. The $\mathrm{Na}$ and $\mathrm{N}$ elemental maps show that the respective monovalent ions $\left(\mathrm{Na}^{+}\right.$and $\left.\mathrm{NH}_{4}^{+}\right)$have different distributions, in the latex: $\mathrm{Na}$ signal within the particles is stronger than in the background, while $\mathrm{N}$ is accumulated at the particle borders. The distributions of surfactant and counter-ions are thus different from some current assumptions, but they support recent results on the distribution of ionic constituents in latex films, by scanning electric potential microscopy.

Keywords: ESI-TEM, latex film, surfactant migration, polymer surface, elemental maps

\section{Introduction}

The recent applications of electron energy loss spectroscopy imaging techniques to transmission electron microscopy $\left(\right.$ ESI-TEM) ${ }^{1}$ are providing new information on the composition of polymer surfaces. ${ }^{2}$ Elemental distribution maps from polystyrene latex particles collected during ab-initio batch and semi-continuous emulsion polymerization revealed that sulfur is uniformly distributed within the particles in both cases, contradicting the usual belief that sulfate polar groups are clustered at the particle surfaces. ${ }^{3}$ Du Chesne and co-workers ${ }^{4}$ mapped sulfur distribution in thin cuts of latex films produced with a sulfate surfactant. They established that the surfactant

\footnotetext{
* e-mail: fernagal@iqm.unicamp.br

\# Present address: Reichhold do Brasil Ltda.
}

segregation to the polymer film surface occurs only if the film is dried at temperatures above the minimum temperature formation (MFFT), and below MFFT the surfactant is retained within the film.

Electric potential gradients within latex films have been demonstrated by using scanning electric potential microscopy (SEPM), ${ }^{5}$ and the first electric potential distribution maps of polymer films and particles were published recently. ${ }^{6,7}$ Transparent films (visible light transmittance $>99 \%$ ), formed by drying a low- $\mathrm{T}_{\mathrm{g}}$ styrenebutyl acrylate-acrylic acid latex often used in paint making, still contain electrically positive boundaries between particles, producing large local electric potential gradients. Aging, annealing and exposure of these films to organic solvent vapors modify the electric domain patterns in the film, evidencing charge clustering and migration. ${ }^{8}$ Charge clustering is not expected in these systems, except at the 
particle interface double-layers, but it probably makes an important contribution to the overall latex film properties. To understand the nature of particle clusters we have to identify the charge-bearing groups. This is possible by using energy-loss spectra and elemental maps acquired by ESI-TEM, since these can detect the elements forming ions in latex, with great sensitivity: sulfur from sulfonate or sulfate, phosphorus from phosphate, sodium, potassium and ammonium counter-ions, and others.

This work presents elemental distribution maps for particle submonolayers of the above-mentioned styrenebutyl acrylate-acrylic acid latex, acquired by ESI-TEM. This latex was chosen for two reasons: its monomer composition is widely used in paints, and the electric potential maps of films made with it are known. ${ }^{8}$

\section{Experimental}

\section{Latex synthesis}

The method and reagents used for preparing the latex and for cleaning up the dispersion were described in a previous paper. ${ }^{8}$ Shortly, the latex was prepared by semicontinuous emulsion polymerization. Initial aliquots of water and surfactants were added to the reactor and heated to $60{ }^{\circ} \mathrm{C}$ under agitation. A pre-emulsion (that is, emulsified water, monomers and surfactants) was continuously added to the reactor for $5 \mathrm{~h}$, simultaneously to the aqueous solutions of ascorbic acid and tert-butyl hydroperoxide (redox initiator). The final dispersion was cooled down, neutralized with ammonia to $\mathrm{pH} 8$ and filtered through a $105 \mu \mathrm{m}$ sieve. Two different surfactants were used during the polymerization: a sulfonate reactive surfactant (Rhodia Sipomer COPS-I) and a non-reactive sodium poly(oxyethylene) phenyl ether phosphate (Rhodafac RE610 , abbreviated as POE in this paper). Prior to sample preparation for ESI-TEM experiments the latex underwent extensive dialysis, to remove low-molecular weight and ionic species. However, this removal is always limited by the requirements of electroneutrality and Donnan effect.

The effective diameters of the latex particles (original and dialyzed) were determined by using photon correlation spectroscopy (PCS), in a ZetaPlus (Brookhaven Inst. Corp.) at $25{ }^{\circ} \mathrm{C}$. The dispersion was diluted to $10^{-4}$ volume fraction prior to the analysis.

Dry film $\mathrm{T}_{\mathrm{g}}$ was determined by DSC. Analyzes were made in a TA $2000^{\mathrm{g}}$ (TA Instruments), within the -80 to $120^{\circ} \mathrm{C}$ temperature range under a $10{ }^{\circ} \mathrm{C} \mathrm{min}{ }^{-1}$ heating rate. Sample weight was approximately $10 \mathrm{mg}$ and the transition temperature was determined from the second run, in order to decrease the influence of film drying and handling stresses.

\section{Sample preparation}

Particle submonolayers (this means, incomplete particle monolayers) used for ESI-TEM experiments were prepared by drying a droplet of a $10^{-4}$ volume fraction dialyzed dispersion on top of the parlodion-carbon film used in the TEM sample holder. Sub-monolayers were chosen for experimental convenience, since single particle thickness is suitable for analytical electron spectroscopy imaging and the effects of particle superimposition are completely avoided, using sub-monolayers. On the other hand, they are easily prepared on top of the thin parlodioncarbon films, just by using well-defined volumes of dispersions of known particle concentration. The samples were dried for at least $24 \mathrm{~h}$, at room temperature over 400 mesh copper grids (Ted Pella) coated with carbon-parlodion films. ${ }^{9}$

The elemental distribution of the latex particle submonolayer was observed using a $80 \mathrm{keV}$ Carl Zeiss CEM 902 transmission electron microscope, equipped with a Castaing-Henry-Ottensmeyer energy filter spectrometer within the column. The images were acquired by a Slow Scan CCD camera (Proscan), and digitalized (1024x1024x8bits) by an image process software analysis (Soft Imaging System), running in a PC computer.

Relevant elemental images present in the latex were obtained using monochromatic electrons with energies corresponding to the K-edge of carbon, nitrogen, sodium and oxygen and the L-edge of the sulfur and phosphorus. The energy-selecting slit was set at $303 \mathrm{eV}$ for C, $410 \mathrm{eV}$ for $\mathrm{N}, 1090 \mathrm{eV}$ for $\mathrm{Na}, 544 \mathrm{eV}$ for $\mathrm{O}, 200 \mathrm{eV}$ for $\mathrm{S}$, and 153 $\mathrm{eV}$ for $\mathrm{P}$, with a $15 \mathrm{eV}$ slit width. ${ }^{10,11}$ The choice of the energy slits was based on the electron energy-loss spectra recorded for these samples in the same microscope and monochromator set-up using the parallel acquisition mode, prior to image acquisition. There are many procedures to extract an elemental map from these images but in this work the three-window method was always used to perform the background subtraction except in the case of phosphorus, when the three-window white line method was applied. In the case of the three-window method, which is the most accurate procedure, one window is positioned at the region of the edge onset of the element in question and the two other windows are positioned at energies below the edge onset. Images acquired at these two windows are used to calculate the background image, this means, the background contribution to the image recorded at the edge onset. Subtraction of the former from the latter produces the elemental distribution map. The three-window method may be applied when the spectral region below the edge is not distorted by the presence of other elements thus 
allowing a good background fitting. In the case of phosphorus, there is a silicon peak near $103 \mathrm{eV}$ and too close to the $153 \mathrm{eV}$ P slit, which distorts the background fitting. The alternative is to use the three-window white line method, positioning two windows below and after the edge onset to record the background, and a third window at the edge. The elemental map is calculated by subtracting the interpolated background from the edge onset image.

\section{Results}

The latex dispersion has $48.2 \%$ weight solids content, as determined by gravimetry following drying at $105^{\circ} \mathrm{C}$ to constant weight. The effective diameter of the asprepared latex was $228 \pm 3 \mathrm{~nm}$, changing to $240 \pm 4 \mathrm{~nm}$ in the dialyzed latex. $\mathrm{T}_{\mathrm{g}}$ of the dry film cast from the asprepared latex (stored for three months after sample preparation) was $15.9{ }^{\circ} \mathrm{C}$, changing to $16.4{ }^{\circ} \mathrm{C}$ in the dialyzed latex (determined by DSC).

Many different images were acquired from submonolayers of latex particles, and representative figures are shown in Figures 1 and 3-8. Figure 1 shows a brightfield picture and an energy-loss $(20 \mathrm{eV})$ dark-field image from a few isolated latex particles. From the bright-field image, we conclude that the latex particles are flattened on top of the supporting film, since their apparent diameter is $c a .350 \mathrm{~nm}$ while the particle effective diameter (determined by PCS within an aqueous dispersion) is $240 \mathrm{~nm}$ only. Particle flattening is understood considering that these particles are from a low- $\mathrm{T}_{\mathrm{g}}$ polymer and that the polymer wets the supporting carbon film. A simple geometric calculation based on volume identity between a sphere with $240 \mathrm{~nm}$ diameter and a cylinder with $350 \mathrm{~nm}$ diameter reveals that the particle average thickness is 68 $\mathrm{nm}$. This is suitable for electron imaging since the $80 \mathrm{keV}$ electron mean free paths for elastic and inelastic scattering within an hydrocarbon compound are respectively $160 \mathrm{~nm}^{12}$ and some hundreds of nanometers. ${ }^{13}$

Particle flattening has to be considered, during the examination of the micrographs given ahead. Elemental distribution maps should also be examined side by side with the corresponding bright-field pictures, because these convey information on the relative thicknesses of adjacent areas in the field under examination. The distribution of a particle constituent can be assessed by considering a few extreme cases, as follows. When the mapped element is uniformly distributed in the particle bulk, then the particle brightness profile should parallel the (inverted) bright-field image profile. On the other hand, if the mapped element is accumulated at the particle surface, the elemental map will display bright rings around the particles. Moreover, the

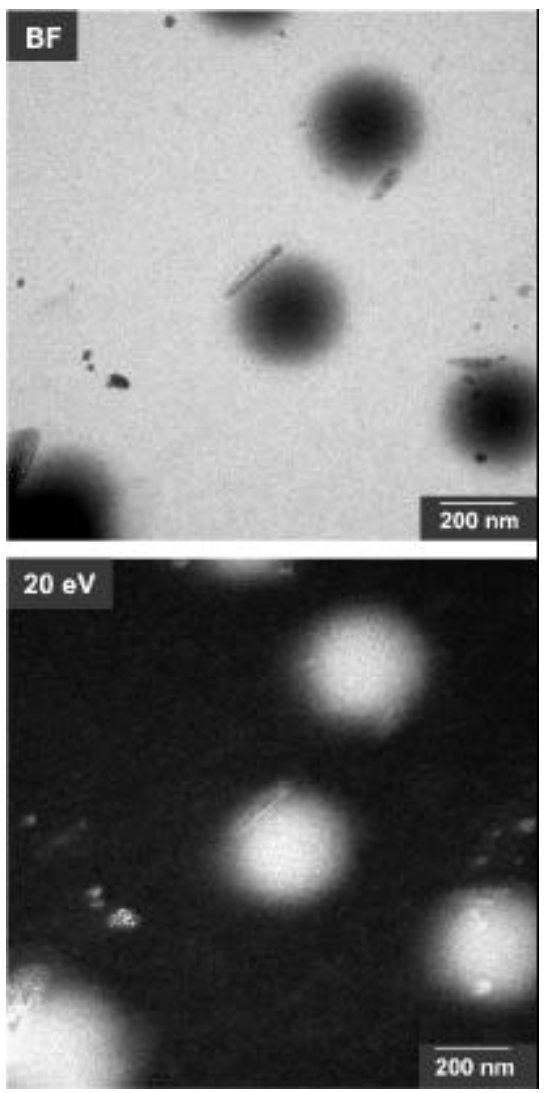

Figure 1. Bright-field (BF) and dark-field $(20 \mathrm{eV})$ images of the same area of the latex sub-monolayer.

accumulation of an element in islands or phase-separated domains is evidenced by bright spots superimposed to the particles, in the elemental maps.

A few unusual and dense particles are also seen in Figure 1 , either at the latex particle borders or scattered in the background. The nature of the various morphological features observed in Figure 1 was elucidated with the help of elemental distribution maps.

Energy-loss elemental mapping is a powerful technique but some imaging artifacts may affect the results. To prevent this, electron energy loss spectra were acquired and used as an evidence for the presence of each element under consideration. These spectra guided the positioning of the window slit, for elemental distribution map acquisition. Spectra in the energy regions corresponding to $\mathrm{C}, \mathrm{S}, \mathrm{P}, \mathrm{N}, \mathrm{O}$ and $\mathrm{Na}$ absorptions are shown in Figure 2. Their quality is highly variable, depending essentially on the amount of the given element in the sample: $\mathrm{C}$ spectrum has a large signal/noise ratio, as expected considering that this is the predominating element in the latex. $\mathrm{O}, \mathrm{N}$ and $\mathrm{Na}$ spectra have lower signal/noise ratios, but the energy threshold for the spectral transition is sufficiently definite for the use of the three-window exponential imaging technique, in all these cases. $\mathrm{P}$ spectrum is more complex, 
requiring the use of the three-window white-line technique, as already mentioned in the Experimental section.

Figure 3 shows $\mathrm{P}$ and $\mathrm{S}$ elemental distribution maps for the same field shown in Figure 1. From these pictures, we observe that $\mathrm{S}$ is dispersed throughout the latex particles. On the other hand, $\mathrm{P}$ is predominantly found outside the particles, either spread in the background or accumulated around some of the denser particles seen in the brightfield image in Figure 1. Particle brightness in the $S$ map increases from the particles surface to the bulk, as expected considering that the sulfonate groups are evenly incorporated to the polymer chains. However, the S-bearing groups are not smoothly distributed, but rather they are accumulated in definite spots, thus evidencing a microphase separation within the particles bulk or at the particle surfaces, with sulfonate-rich domains dispersed in a polymer matrix. Beyond the background and the denser
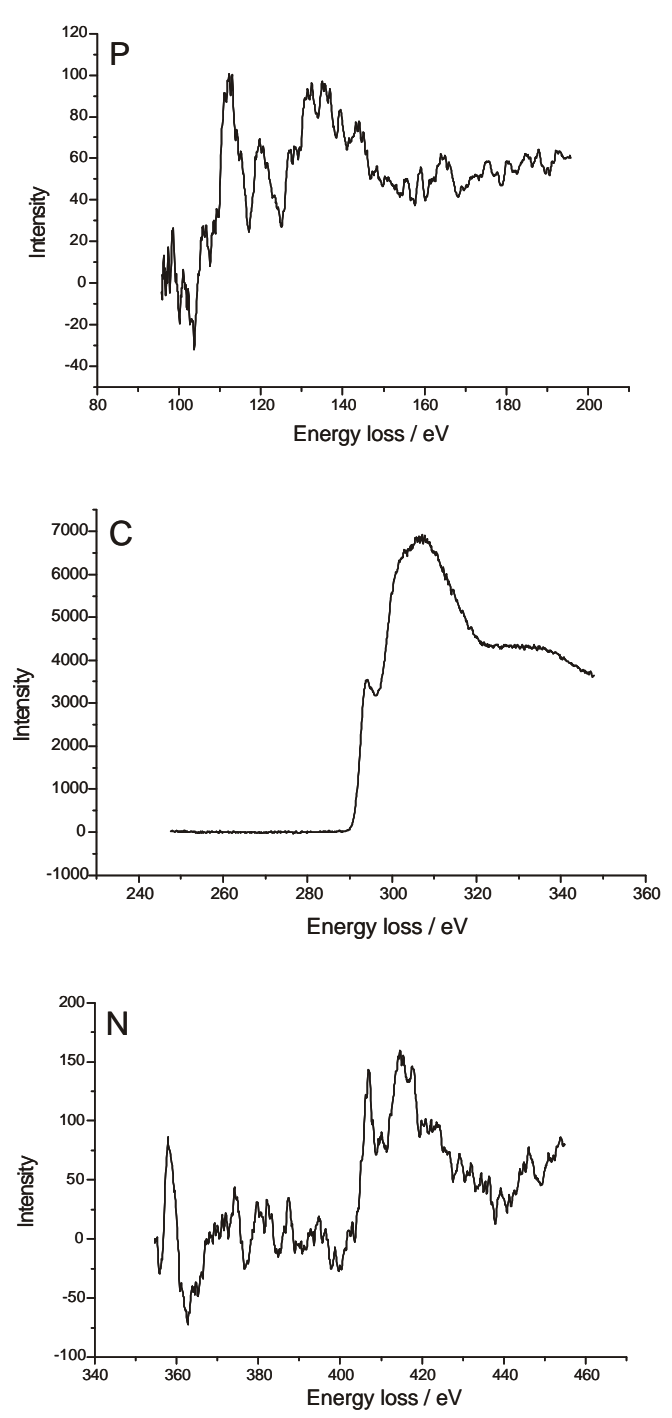

particles, phosphate is perceived closer to the rim of the (particle) discs in the $\mathrm{P}$ map. These are thus sites for $\mathrm{P}$ accumulation together with $\mathrm{N}$ and $\mathrm{O}$ (see ahead). In these flattened particles, phosphate accumulation at the particle surfaces would produce a rather even brightness across the particle discs, but increasing at their borders; this is not seen, thus excluding extensive accumulation at the surfaces. Phosphate exclusion from the particles bulk may seem trivial, since the phosphate surfactant is not reactively incorporated to the polymer chains. However, the following points should be considered, to understand these results. First, P maps do not allow a distinction between unhydrolyzed phosphate surfactant, orthophosphate ions or other P species formed by hydrolysis. On the other hand, $\mathrm{S}$ maps are only dependent on the sulfonate surfactant distribution, since this is resistant to hydrolysis. Second, previous work using latex prepared with non-reactive
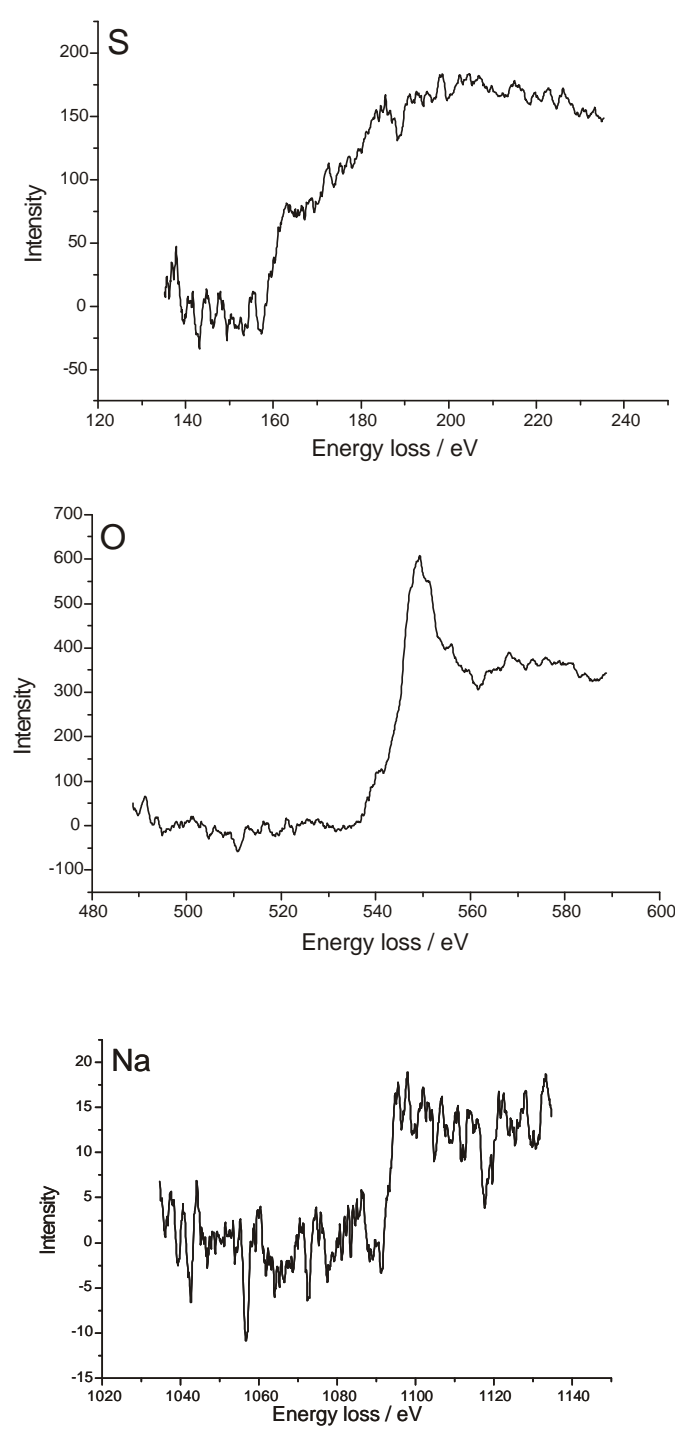

Figure 2. EELS spectra of the latex submonolayer from the fields where the respective elemental maps were taken, in the energy regions corresponding to $\mathrm{C}, \mathrm{S}, \mathrm{P}, \mathrm{N}, \mathrm{O}$ and $\mathrm{Na}$ absorption thresholds. 
sulfate surfactants showed sulfate dispersed within the particles, without any evidence for sulfate segregation to the surface, in the dry particles. ${ }^{3,6}$ Third, the phosphate groups at the particle surfaces are strongly accumulated at some points, instead of being distributed over the surface, as it would be expected following an usual surfactant adsorption model. Finally, the sulfonate groups are also found in the P-rich domains but only at their rims, in a clear evidence of the mutual exclusion of sulfonate and phosphate groups.
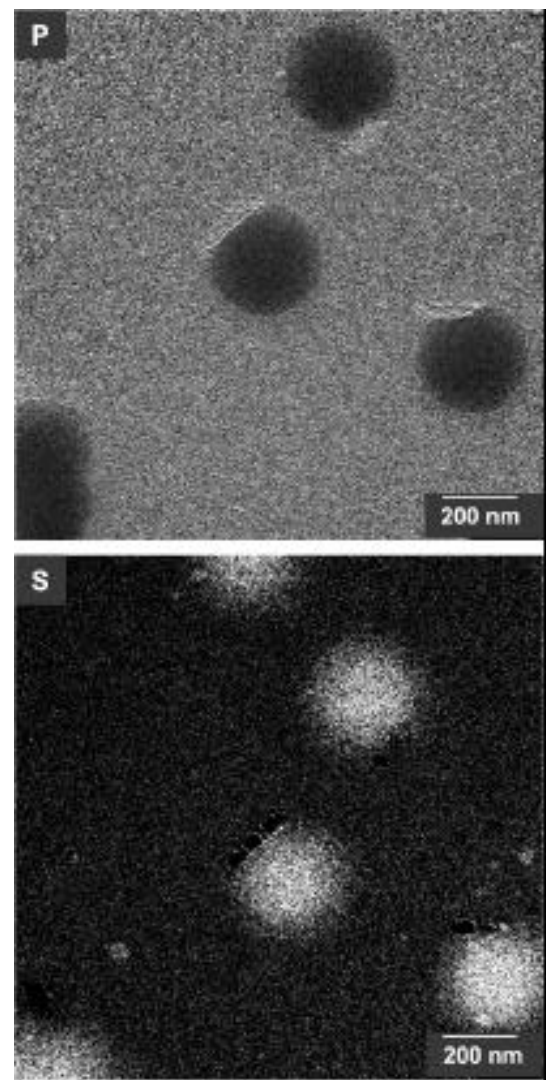

Figure 3. Phosphorus $(\mathrm{P})$ and sulfur (S) elemental distribution maps of the same area shown in Figure 1.

Many attempts were made to obtain bright-field images and multi-element (C, N, Na, O) maps from the same sets of particles, as we presented in previous publications. ${ }^{3,5,7,9}$ However, the present particles did not resist beam damage, during the long required beam exposures. For this reason, Figures 4-6 show bright-field images together with only one or two elemental maps each.

The following observations are made therefrom: $i$ ) as expected, $\mathrm{C}$ (shown in Figure 4) predominates within the latex particles, and it is mostly absent from the denser smaller particles as well as from the interior of the unusual particles seen at the latex particle borders. However, a thin brighter line surrounds these particles in the $\mathrm{C}$ map,

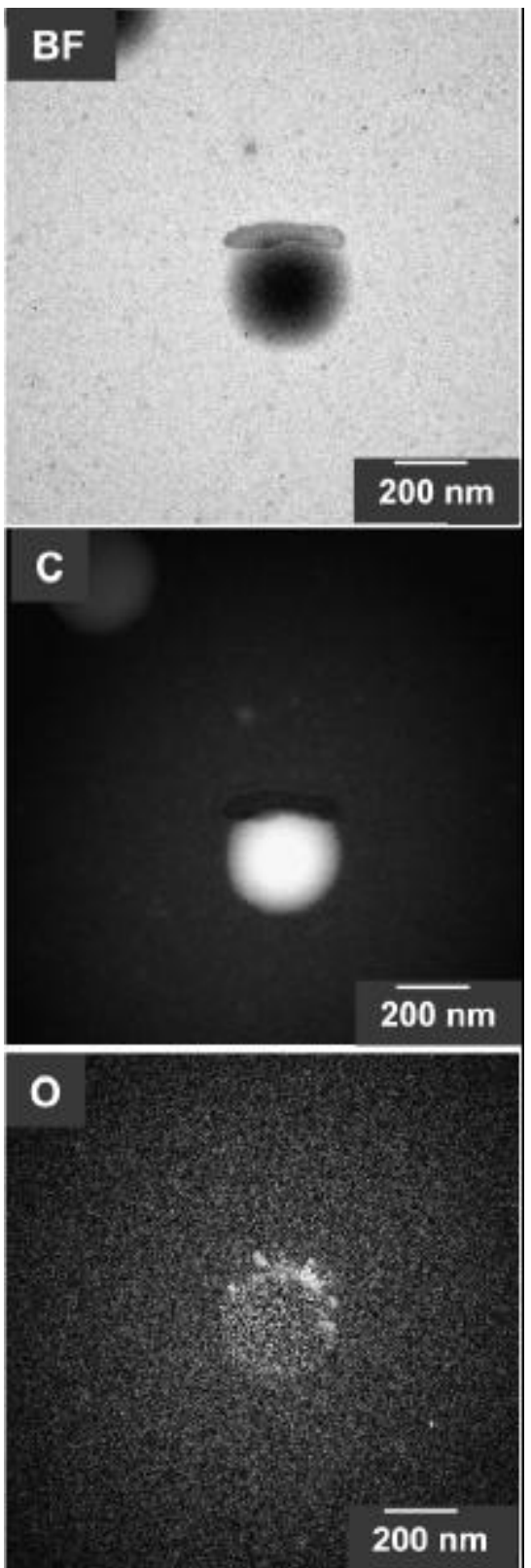

Figure 4. Bright-field (BF) image and carbon (C) and oxygen (O) elemental distribution maps.

showing that they are coated by surfactant. Considering the $\mathrm{S}$ and $\mathrm{P}$ maps, both types of surfactants surround these particles; $i$ i) $\mathrm{O}$ is found around the latex particles but also within them, and in the background. Opposite to the $\mathrm{C}$ signal, the $\mathrm{O}$ signal is more intense in the particle disc rims, probably due to the expected accumulation of acrylic monomers closer to the particle surface. It is also found in the unusual structures in the latex particle borders, but strongly concentrated in a few spots; iii) $\mathrm{N}$ and $\mathrm{Na}$ are detected in the particles as well as in the background. However, the $\mathrm{N}$ map shows brighter spots at the particle borders evidencing an accumulation of this element on 


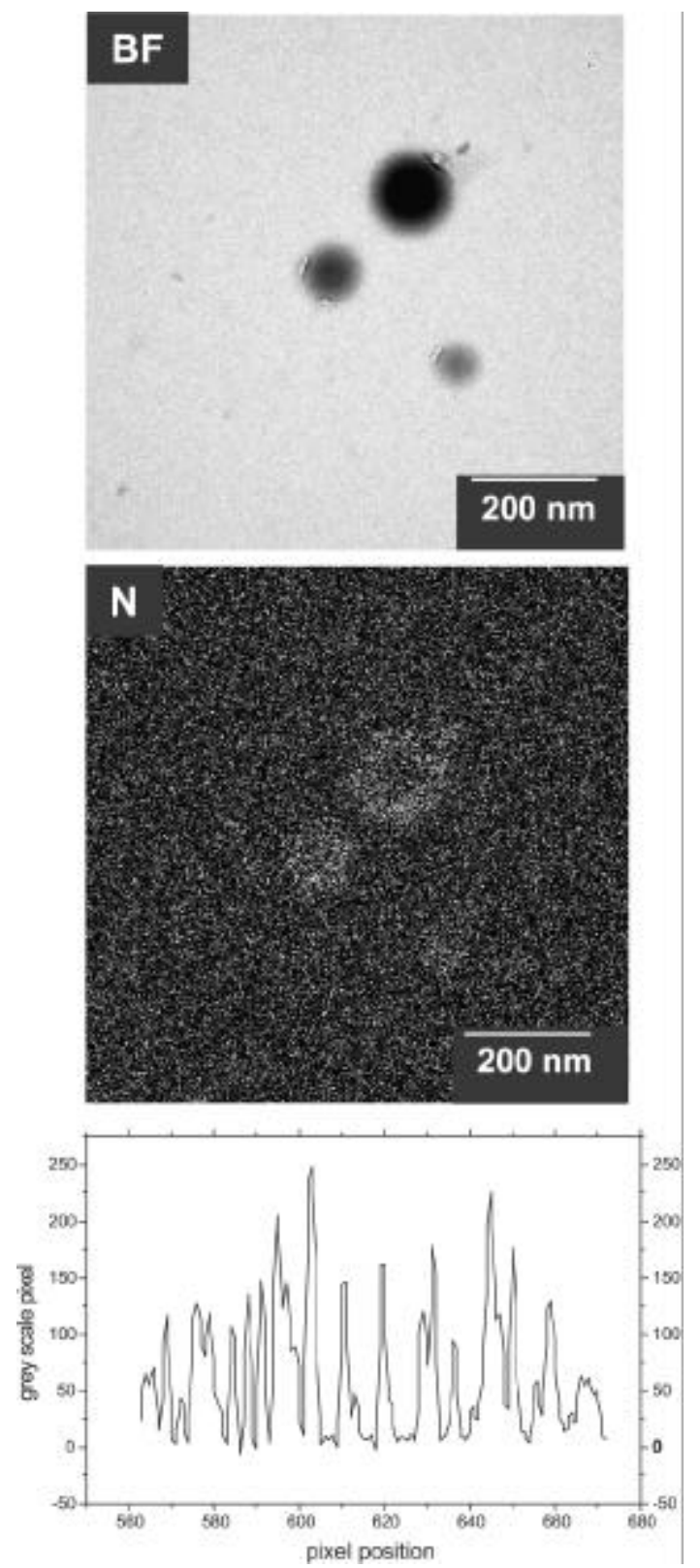

Figure 5. Bright-field (BF) image and nitrogen $(\mathrm{N})$ elemental distribution map. The lower plot is a line-scan made in the $\mathrm{N}$ map, from top to bottom of the white line drawn across the particle.

the particle shell (and thus together with $\mathrm{P}$ and O). Since the $\mathrm{N}$ image is very spotty (or else, pixel brightness varies sharply), $\mathrm{N}$ accumulation is better seen by comparing the line-scan in Figure 5 with the line-scan for sodium distribution in Figure 6, in which the moving average of the line has a maximum in the particle center.

A different information comes from Figure 7, comparing the bright-field and diffractive dark-field images for the same field: the darker areas in the brightfield are not uniformly bright in the dark-field, showing that these denser regions are made out of more ordered, polycrystalline material.
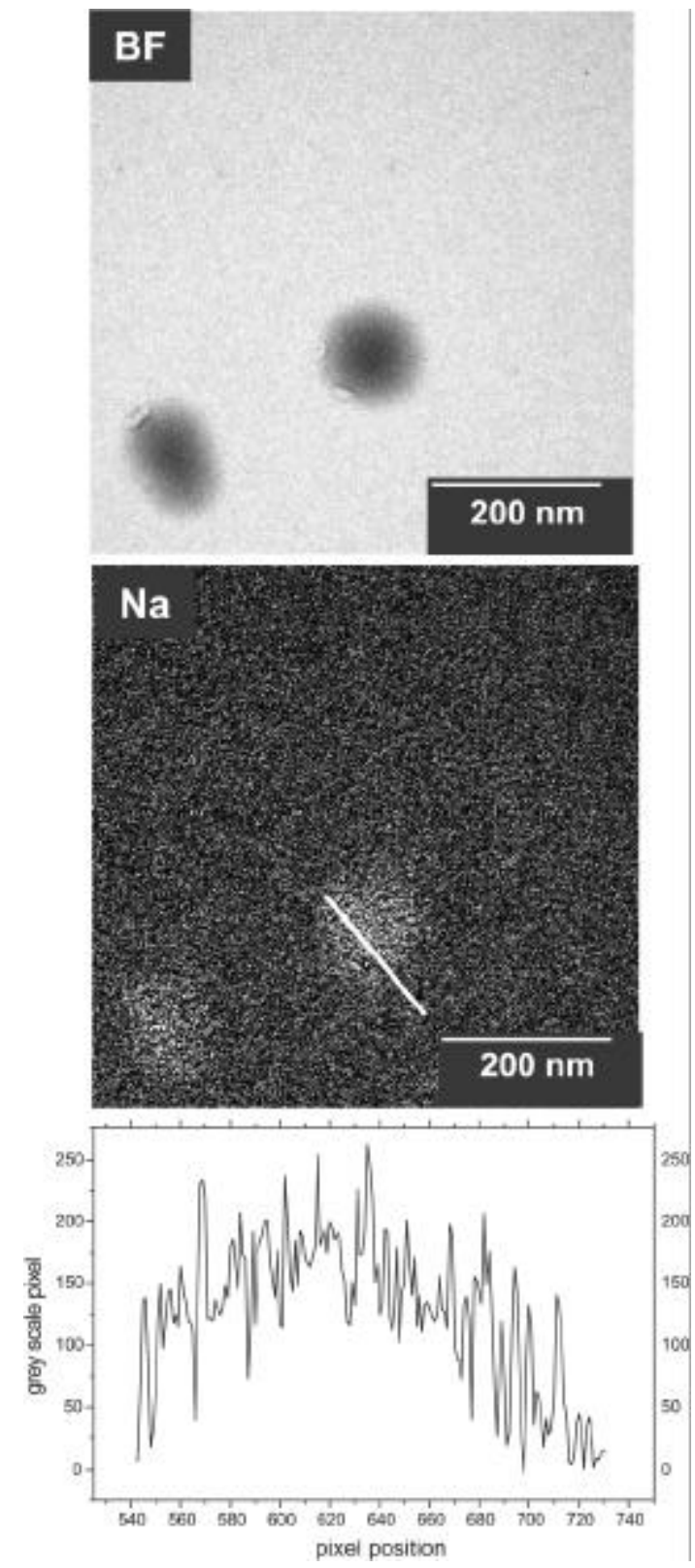

Figure 6. Bright-field (BF) image and sodium (Na) elemental distribution map. The lower plot is a line-scan made in the Na map, from top to bottom of the white line drawn across the particle.

EELS spectra can be acquired from very small areas, and this was used to identify carbon composition changes within the latex particles, as shown in Figure 8. The two spectra from the particle centers (points 4 and 5) are indistinguishable, within the experimental error, but the spectra from particle borders (points 2 and 3) and the background (point 1) are quite different. The $\mathrm{C}$ absorption from the structure seen at the border (point 2) has a slightly higher intensity than the background. The spectrum on the other point (point 3 ) at the film border has pronounced differences with the spectra from the particle centers (points 4 and 5). Peak intensity is lower in 3 and also the line- 


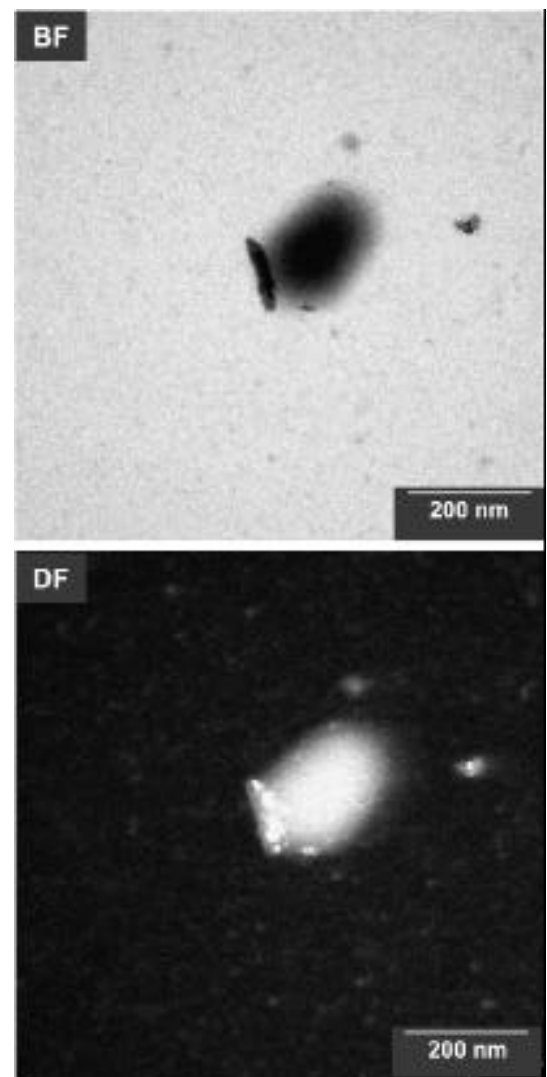

Figure 7. Bright-field (BF) and dark-field (DF) images of a particle in a submonolayer. The dark-field image is acquired using elastically scattered or diffracted electrons.

shape above $310 \mathrm{eV}$ is different from all others, evidencing that the polymer in this region is different from the polymer at the particle core. This is in agreement with the expectation that the particle outer and inner layers should not have identical monomer distribution, in copolymer latex formed by two monomers of different polarity. ${ }^{14} \mathrm{On}$ the other hand, this supports the observation of $\mathrm{O}$ accumulation at the flattened particle outer layers, due to increased acrylic monomer content.

\section{Discussion}

The small $\mathrm{T}_{\mathrm{g}}$ difference between the films formed with original and dialyzed latexes shows that the free surfactant present in the serum of the original latex does not have a significant role in polymer plastification.

Following dialysis, the particle effective diameters are $12 \mathrm{~nm}$ larger than in the original dispersion. This may be understood, considering that particles undergo stronger swelling at low ionic strength, and protruding chain ends ("hairs") at the particle surface should extend longer than at higher ionic strength. ${ }^{15}$

The $\mathrm{C}, \mathrm{O}, \mathrm{S}$ and $\mathrm{P}$ maps help us to understand some
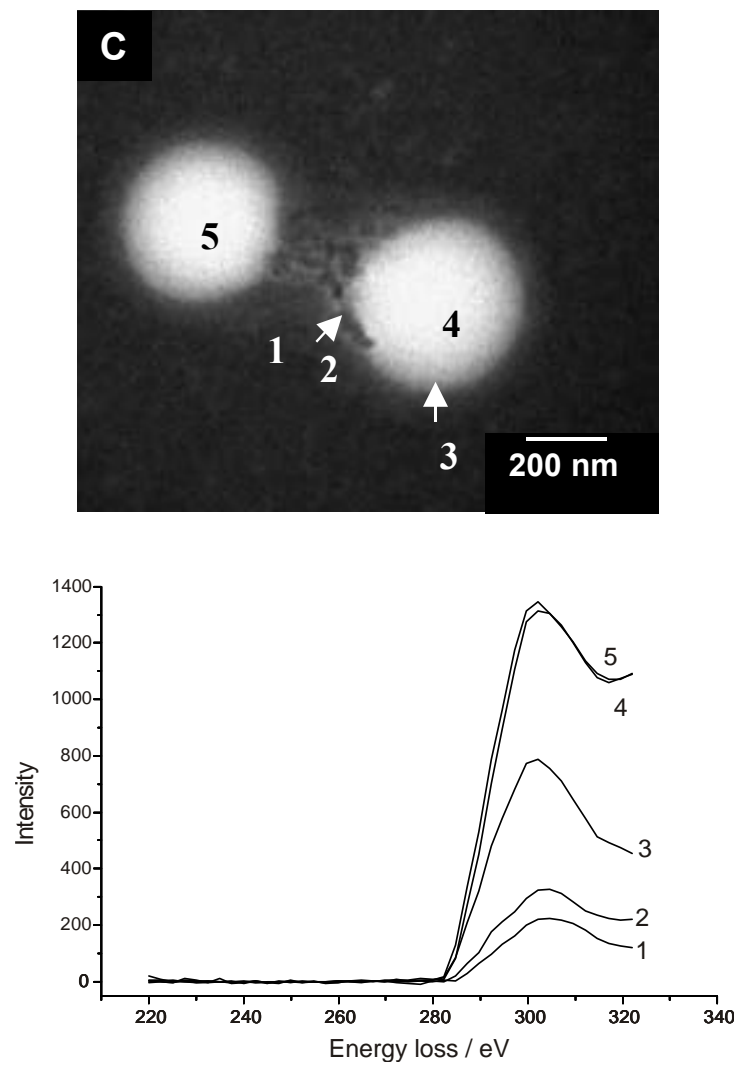

Figure 8. Carbon elemental map of a pair of particles (above), and the EELS spectra acquired from the areas numbered 1 to 5 on the $\mathrm{C}$ map (below).

characteristics of the latex particles and the formed film. The high-density material often found at the particle borders is highly heterogeneous and certainly immiscible with the polymer. As compared to the particles, this material has a higher phosphorus and oxygen content, but lower carbon and sulfur content. Sulfur-rich domains are the loci for incorporation of the reactive surfactant, and they are well distributed throughout the polymer, thus confirming that the covalently bound surfactant is uniformly distributed in the polymer particles, as found by using contact angle measurements ${ }^{16}$ and atomic force microscopy $(\mathrm{AFM}){ }^{17}$

On the other hand, the $\mathrm{P}$ atoms introduced with the non-reactive phosphate surfactant cannot be covalently bound to the polymeric chains. The P maps show that the phosphate groups are excluded from the particles center and also they are often dissociated from $\mathrm{C}$ groups. $\mathrm{P}$ accumulates in a thick particle shell and specially at the particle borders as well as in the serum, as shown by the gray background in the $\mathrm{P}$ elemental map. Consequently, $\mathrm{P}$ is partly present as inorganic phosphate with a low compatibility to the polymer surface, forming dense separated domains but still adherent to the particle borders. 
This also shows that the phosphate surfactant underwent extensive hydrolysis, during latex preparation and storage.

In a previous paper, ${ }^{8}$ SEPM images revealed that particle interfaces were observed up to 2 months after a transparent film of this styrene-butyl acrylate-acrylic acid latex was formed at room temperature. The interior of particles in the film was electrically more negative than the interparticle borders. We can now state that these negative domains were predominantly due to sulfonate, rather than phosphate groups. In a superficial evaluation, sulfonate distribution throughout the particles could be assigned to the use of reactive surfactant. However, the same pattern has already been observed by using non-reactive surfactants. ${ }^{3,6}$ Further aging of the same sample for 3 months produced both a new film surface topography pattern and a new distribution of electric domains, evidencing the mobility of ionic species in the film.

Due to the strict thickness requirements of energy-loss imaging, the films examined in the present work are indeed sub-monolayers, while the previous AFM and SEPM measurements were made on thicker films. Surfactant may be trapped within a drying thick film, due to the longer times required to migrate to the film surface. As Urban and Zhao have demonstrated, as part of the drying process the particles come into contact during water evaporation. The particles are deformed and the surfactant and water-soluble ionic species (including orthophosphate) present in their surfaces form aggregates within the continuous film, wherefrom they can migrate. ${ }^{18}$

Fitch and McCarvill ${ }^{19}$ has demonstrated that sulfate compounds, present on the particle surfaces, are easily hydrolyzed. This causes a reduction in the latex stability and a $\mathrm{pH}$ reduction, due to the sulfuric acid formation. In the present case, we have not observed a significant $\mathrm{pH}$ decrease after 6 months storage, thus suggesting the absence of surfactant phosphate hydrolysis. However, the present microanalytical data shows the presence of species loaded with $\mathrm{P}$ but devoid of $\mathrm{C}$, this means, inorganic phosphates. Consequently, the pH stability is to be assigned to the buffering capacity of phosphate ions, rather than to phosphate surfactant stability towards hydrolysis.

Regarding the counter-ions maps, $\mathrm{N}$ is more concentrated in the film border than in its interior, and it is also found in the background and thus in the latex serum. $\mathrm{N}$ is introduced in the latex as the ammonia used for neutralization made at room temperature when the particles are already formed and the monomer is used up. The present results show that the ammonium counter-ions did not strongly diffuse into the particles, as opposed to $\mathrm{Na}$, which is significantly accumulated within them. This difference in the behavior of the two monovalent ions suggests that latex properties may be tuned by changing the counterions used. Moreover, $\mathrm{N}$ accumulation at the particle border is superimposed to $\mathrm{O}$ accumulation, suggesting that ammonium ions accumulate at the more hydrophilic particle sites, more markedly than sodium ions.

Counter-ion partitioning may have an important role in latex films properties, because charge accumulation at some spots will probably affect film cohesion, swelling, interfacial and phase separation phenomena. However, since the acknowledgement of this new factor is very recent, we still do not have sufficient data to evaluate its relevance. ${ }^{20}$

\section{Conclusions}

The distribution of sulfur and phosphorus (originated from the non-reactive POE-phosphate and the reactive sulfonate surfactants used in the latex polymerization, or their decomposition products) is completely different, in the latex particle submonolayers. Phosphate residues are nearly absent from the interior of the latex particles, they are observed in a thick particle outer ring but they are also detected as inorganic phosphate in unusual, strongly scattering structures adhering to the latex particle borders, and in the background. On the other hand, the reactive sulfonate surfactant is uniformly distributed within the polymer particles.

The $\mathrm{Na}$ and $\mathrm{N}$ elemental maps are also different, showing that the corresponding monovalent ions $\left(\mathrm{Na}^{+}\right.$and $\mathrm{NH}_{4}^{+}$) are partitioned independently, between the latex and the serum, and $\mathrm{NH}_{4}{ }^{+}$accumulates in the more hydrophilic particle outer rings.

The existence of many charged species with independent distribution patterns in the latex monolayers is consistent with the rich and complex patterns of electric charge cluster formation and mobility, recently revealed by SEPM.

\section{Acknowledgements}

FG thanks Fapesp, Pronex/Finep and CNPq for continuing support. AJK held a Fapesp pre-doctoral fellow. This is a contribution from the Millenium Institute of Complex Materials/MCT.

\section{References}

1. Egerton, R. F.; Electron Energy-Loss Spectroscopy in the Electron Microscope, Plenum Press: New York, 1986.

2. Du Chesne, A.; Macromol Chem. Phys. 1999, $200,1813$.

3. Amalvy, J. I.; Asua, J. M.; Leite, C. A. P.; Galembeck, F.; Polymer 2001, 42, 2479. 
4. Du Chesne, A.; Gerharz, B.; Lieser, G.; Polym. Int. 1997, 43, 187.

5. Cardoso, A. H.; Leite, C. A. P.; Galembeck, F.; Colloids Surf., A 2001, 181, 49.

6. Braga, M.; Costa, C. A. R.; Leite, C. A. P.; Galembeck, F.; J. Phys. Chem. B 2001, 105, 3005.

7. Galembeck,A.; Costa, C. A. R.; Silva, M. C. V. M.; Souza, E. F.; Galembeck, F.; Polymer 2001, 42, 4845.

8. Keslarek, A. J.; Costa, C. A. R.; Galembeck, F.; Langmuir 2001, 17, 7886.

9. Cardoso, A. H.; Leite, C. A. P.; Galembeck, F.; Langmuir 1998, 14, 3187.

10. Reimer, L.; Zepke, U.; Moesch, J.; Schulze-Hillert, St.; RossMessemer, M.; Probst, W.; Weimer, E.; EELS Spectroscopy: A Reference Handbook of Standard Data for Identification and Interpretation of Electron Energy Loss Spectra and for Generation of Electron Spectroscopic Images, Carl Zeiss: Oberkochen, 1992.

11. Reimer, L.; Mater. Trans. JIM 1998, 39, 873.

12. Newbury, D. E. In Principles of Analytical Electron Microscopy; Joy, D. C.; Romig, A. D. Jr.; Goldstein, J. I., eds; Plenum Press: New York, 1986, p. 8.
13. Klotz, S.; von Seggern, J.; Kunz, M.; Cantow, H-J.; Polym. Commun. 1990, 31, 332

14. El-Aasser, M.S.; Hu R; Dimonie, V. L.; Sperling, L. H.; Colloids Surf., A 1999, 153, 241.

15. Butt, H-J.; Gerharz, B.; Langmuir 1995, 11, 4735.

16. Wang, X.; Sudol, E.D.; El-Aasser, M. S.; J. Polym. Sci. Pol. Chem. 2001, 39, 3093.

17. Lam, S.; Hellgren, A. C.; Sjoberg, M.; Holmberg, K.; Schoonbrood, H. A. S.; Unzue, M. J.; Asua, J. M.; Tauer, K.; Sherrington, D. C.; Goni, A. M.; J. Appl. Polym. Sci. 1997, 66, 187.

18. Zhao, Y.; Urban, M. W.; Macromolecules 2000, 33, 2184.

19. Fitch, R. M.; McCarvill, W. T.; J. Coll. Interf. Sci. 1978, 66, 20.

20. Galembeck, F.; Costa , C. A. R.; Galembeck, A.; Silva, M. C. V. M.; An. Acad. Bras. Cienc. 2001, 73, 495.

Received: February 12, 2003

Published on the web: January 19, 2004

FAPESP helped in meeting the publication costs of this article. 